\title{
Removal of copper ions from contaminated groundwater using waste foundry sand as permeable reactive barrier
}

\author{
A. A. H. Faisal • M. D. Ahmed
}

Received: 19 December 2013/Revised: 17 March 2014/ Accepted: 2 September 2014/Published online: 24 September 2014

(C) Islamic Azad University (IAU) 2014

\begin{abstract}
Computer solutions Multiphysics 3.5a software was used for simulating the two-dimensional copper migration including sorption process through the saturated zone of the soil in the presence of permeable reactive barrier for equilibrium condition. The 1:3 mixture of waste foundry sand and Kerbala's sand was used as filling material for this barrier. The waste foundry sand was represented the reactivity material, while Kerbala's sand used to increase the permeability of reactive barrier only. However, Fourier transform infrared analysis proved that the carboxylic and alkyl halide groups are responsible for the sorption of copper onto waste foundry sand. Batch tests have been performed to characterize the equilibrium sorption properties of the waste foundry sand and Kerbala's sand mix in copper-containing aqueous solutions. Numerical and experimental results proved that the permeable reactive barrier plays a potential role in the restriction of the contaminant plume migration. Also, predicted results showed that the thicker barrier is better than the thinner ones in copper treatment, and this barrier saturates with contaminant as a function of the travel time. However, a good agreement between the predicted and experimental results was recognized with mean error not exceeded $10 \%$.
\end{abstract}

Keywords Saturated zone - Water pollution - Transport . Underground

\footnotetext{
A. A. H. Faisal $(\bowtie) \cdot$ M. D. Ahmed

Department of Environmental Engineering, College of

Engineering, University of Baghdad, Baghdad, Iraq

e-mail: ayadabedalhamzafaisal@yahoo.com
}

\section{Introduction}

Heavy metals are among the most dangerous inorganic water pollutants, they can be related to many anthropogenic sources, and their compounds are extremely toxic. These metals, such as cadmium, chromium, copper, mercury, lead, cannot be degraded and, consequently, can be accumulated in the aquatic food web reaching human beings through the food chain, and causing several pathologies. This means that the exposure to these pollutants especially through dietary intake of plant-derived food and beverages, or drinking water can have long-term effects on human health. The presence of heavy metals in groundwater is due to water exchange with contaminated rivers and lakes or to leaching from contaminated soils by rainfall infiltration (Yeung 2005 as cited by Di Natale et al. 2008; Singh et al. 2009; Khan et al. 2011).

The most common technology used historically for remediation of groundwater has been ex situ pump-andtreat systems. These systems extract groundwater to the surface, treat it by different approaches such as adsorption and either re-introduce the treated water to the subsurface or discharge it to a storm drain. This technique is difficult, costly and ineffective most of the time in removing enough contamination to restore the groundwater to drinking water standards in acceptable time frames (National Research Council 1994). Accordingly, permeable reactive barriers (PRBs) technology was alternative method used to remediate groundwater contaminated with different types of contaminants. It is found to be more cost-effective than pump-and-treat systems and has been a demonstrated potential to diminish the spread of contaminants. The advantages of this approach include treatment of contaminants in the subsurface, complete plume capture, a passive (low energy) treatment approach that has considerably 
lower operation and maintenance costs and lower longterm performance monitoring costs (Powell et al. 2002).

A set of theoretical and experimental studies on PRBs using different types of reactive medium such as activated carbon, zeolite, zero-valent iron (ZVI) and others for removal of heavy metals from polluted groundwater has been achieved. A batch and column tests were conducted to determine the design factors for clinoptilolite, one of the natural zeolites, PRBs against the contaminated groundwater by ammonium and heavy metals (Park et al. 2002). The potential use of waste foundry sand (WFS) as an inexpensive medium for PRBs was studied. Batch and column tests were conducted to evaluate the reactivity and sorptive capacity of twelve foundry sands for four groundwater contaminants: trichloroethylene (TCE), the herbicides alachlor and metolachlor, and zinc (Lee and Benson 2002). A set of tests to determine the feasibility of using waste green sands as a low-cost reactive medium for groundwater treatment was achieved. Batch and column tests were conducted to determine the reactivity, sorptive characteristics and transport parameters for TCE solutions in contact with green sands (Lee et al. 2004). The potential application of activated carbon in PRB for the removal of cadmium was investigated. The adsorption isotherms of this material are experimentally determined, and a theoretical model is proposed for the interpretation of experimental results (Di Natale et al. 2008). A continuous column experiment was carried out under dynamic flow conditions in order to study the efficiency of low-cost PRBs to remove several inorganic contaminants from acidic solutions. A 50:50 w/w waste iron/sand mixture was used as the candidate reactive media in order to activate precipitation and promote sorption and reduction-oxidation mechanisms (Bartzas and Komnitsas 2010). Column tests with three configurations of reactive material (ZVI only, granular mixture of ZVI and pumice, and pumice and ZVI in series) using aqueous nickel and copper solutions of various concentrations are studied (Moraci and Calabrò 2010). Numerical modeling was developed for 1D solute transport including chemical reaction to simulate the PRB column results, in which arsenite (As(III)) was removed using ZVI (Eljamal et al. 2011). A three-dimensional groundwater flow model was developed to evaluate the performance of ZVI and activated sludge as reactive media for the continuous and funnel and gate PRBs. Simulation results showed that funnel and gate PRBs have similar performance with the continuous PRBs on treating zinc-contaminated groundwater but having less operation time (Chalermyanont et al. 2013). A 1D numerical finite difference model was developed to describe cadmium transport within groundwater taking its sorption on the PRB into account (Faisal and Hmood 2013). Many other studies (Ambrosini 2004; Woinarski et al. 2006; Geranio 2007;
Bazdanis et al. 2011; Plamondon et al. 2011; Suponik 2010, 2013) were achieved to study the performance and efficacy of this technology under different conditions.

However, the foundry industry releases large quantities of by-product WFS, which represent both a waste and a pollutant. For example, Nasr Company for Mechanical Industries, Special Steel Foundry/Iraq produced 10 tons of WFS per $8 \mathrm{~h}$ when worked with full capacity. One can be expected the huge generated quantities of this material which be banished to the ecosystem. Thus, reusing of this waste as a reactive medium is attractive in terms of sustainable development and also allows the foundry industry to accrue savings through reduced disposal costs (Lee et al. 2004; Siddique et al. 2010; Oliveira et al. 2011). Thus, the significance of the present study is : (1) investigation the potential application of WFS as an inexpensive material in PRBs for the removal of copper $\left(\mathrm{Cu}^{2+}\right)$ from the contaminated groundwater; (2) determining the predominant factional groups which are responsible of $\mathrm{Cu}^{2+}$ removal in the WFS using Fourier transform infrared (FTIR) spectroscopy analysis; and (3) characterization the 2D equilibrium transport of $\mathrm{Cu}^{2+}$ theoretically, using computer solutions (COMSOL) Multiphysics 3.5a (2008) software which is based on finite element method, and experimentally through simulated subsurface aquifer and WFS barrier under saturated condition.

The present study was achieved at the laboratories of the Environmental Engineering Department, University of Baghdad, Iraq, during the period ranged from October 2012 to September 2013.

\section{Materials and methods}

\section{Materials}

The WFS (Table 1) used in the present study had a particle size distribution ranged from $75 \mu \mathrm{m}$ to $1 \mathrm{~mm}$ with an effective grain size, $d_{10}$, of $180 \mu \mathrm{m}$, a median grain size, $d_{50}$, of $320 \mu \mathrm{m}$ and a uniformity coefficient, $C_{\mathrm{u}}$, of 1.94 . As the hydraulic conductivity of this sand was very low $\left(=1 \times 10^{-6} \mathrm{~cm} / \mathrm{s}\right)$, it is mixed with Kerbala's sand (KS). The 1:3 mixture of (WFS + KS) was used with achieved conductivity equal to $3 \times 10^{-3} \mathrm{~cm} / \mathrm{s}$. Also, the bulk density and porosity of this tested reactive mixture are $1.55 \mathrm{~g} /$ $\mathrm{cm}^{3}$ and 0.38 , respectively.

The sandy soil, with porosity of 0.409 , was used as aquifer in the conducted experiments. This soil had a particle size distribution ranged from $75 \mu \mathrm{m}$ to $2 \mathrm{~mm}$ with an effective grain size, $d_{10}$, of $280 \mu \mathrm{m}$, a median grain size, $d_{50}$, of $240 \mu \mathrm{m}$ and a uniformity coefficient, $C_{\mathrm{u}}=d_{60} / d_{10}$, of 1.54 . The hydraulic conductivity and bulk density equal to $2 \times 10^{-3} \mathrm{~cm} / \mathrm{s}$ and $1.567 \mathrm{~g} / \mathrm{cm}^{3}$. 
Table 1 Composition and physicochemical properties of WFS

\begin{tabular}{ll}
\hline Property & Value \\
\hline $\mathrm{SiO}_{2}(\%)$ & 94.36 \\
$\mathrm{Al}_{2} \mathrm{O}_{3}(\%)$ & 2.82 \\
$\mathrm{Fe}_{2} \mathrm{O}_{3}(\%)$ & 2.12 \\
$\mathrm{Na}_{2} \mathrm{O}(\%)$ & 0.24 \\
$\mathrm{CaO}(\%)$ & 0.05 \\
$\mathrm{TiO}_{2}(\%)$ & 0.14 \\
$\mathrm{MgO}(\%)$ & 0.23 \\
$\mathrm{~K}_{2} \mathrm{O}(\%)$ & 0.039 \\
$\mathrm{Bulk}$ density $\left(\mathrm{g} / \mathrm{cm}^{3}\right)$ & 1.44 \\
$\mathrm{Particle}$ density $\left(\mathrm{g} / \mathrm{cm}^{3}\right)$ & 2.67 \\
Porosity & 0.46 \\
Surface area $\left(\mathrm{m}^{2} / \mathrm{g}\right)$ & 5.9351 \\
Cation exchange capacity (meq/100 g) & 10.94 \\
\hline
\end{tabular}

Copper was selected as a representative of heavy metal contaminants. To simulate the water's copper contamination, a solution of $\mathrm{CuSO}_{4} .5 \mathrm{H}_{2} \mathrm{O}$ (manufactured by Germany) was prepared and added to the specimen to obtain representative concentration.

\section{Batch experiments}

Batch equilibrium tests are carried out to specify the best conditions of contact time, initial $\mathrm{pH}$, initial concentration, (WFS + KS) dosage and agitation speed. Series of 250-ml flasks are employed and each flask is filled with $100 \mathrm{ml}$ of copper solution which has initial concentration of $50 \mathrm{mg} / \mathrm{l}$. One gram of (WFS + KS) was added into different flasks, and these flasks were kept stirred in the high-speed orbital shaker at $250 \mathrm{rpm}$ for $4 \mathrm{~h}$. A fixed volume $(20 \mathrm{ml})$ of the solution was withdrawn from each flask. This withdrawn solution was filtered to separate the sorbent and a fixed volume $(10 \mathrm{ml})$ of the clear solution was pipetted out for the concentration determination of the copper ion still present in solution. The measurements were carried out using atomic absorption spectrophotometer (AAS) (Norwalk, Connecticut (USA)). These measurements were repeated for two times and average value has been taken. However, the adsorbed concentration of metal ion on the $(\mathrm{WFS}+\mathrm{KS}$ ) was obtained by a mass balance.

The effect of various parameters such as initial $\mathrm{pH}(2$, 4, 6.5 and 8), initial $\mathrm{Cu}^{2+}$ concentration $(50,100,150$, 200 and $250 \mathrm{mg} / \mathrm{l})$, (WFS $+\mathrm{KS})$ dosage $(0.25,0.5,1,3$ and $5 \mathrm{~g})$ and agitation speed $(0,50,100,150,200$ and $250 \mathrm{rpm}$ ) was studied in term of their effect on removal efficiency. The amount of metal ion retained on the $(\mathrm{WFS}+\mathrm{KS}), q_{\mathrm{e}}$ in $(\mathrm{mg} / \mathrm{g})$, was calculated as follows (Wang et al. 2009):
$q_{\mathrm{e}}=\left(C_{\mathrm{o}}-C_{\mathrm{e}}\right) \frac{V}{m}$

where $C_{\mathrm{o}}$ is the initial concentration of copper in the solution $(\mathrm{mg} / \mathrm{l}), C_{\mathrm{e}}$ is the equilibrium concentration of copper remaining in the solution $(\mathrm{mg} / \mathrm{l}), V$ is the volume of solution (1) and $m$ is the mass of (WFS + KS) (g).

Langmuir [Eq. (2)] and Freundlich [Eq. (3)] models are used for the description of sorption data as follows (Watts 1998):

$q_{\mathrm{e}}=\frac{a b C_{\mathrm{e}}}{1+b C_{\mathrm{e}}}$

where $a$ is empirical constant and $b$ is the saturation coefficient $(1 / \mathrm{mg})$.

$q_{\mathrm{e}}=K_{\mathrm{F}} C_{\mathrm{e}}^{1 / n}$

where $K_{\mathrm{F}}$ is the Freundlich sorption coefficient and $n$ is an empirical coefficient.

\section{Continuous experiments}

The simulated $\mathrm{Cu}^{2+}$ transport was performed in a twodimensional tank schematically shown in Fig. 1. This bench-scale model aquifer is contained within a rectangular 6-mm-thick acrylic glass tank $(100 \mathrm{~cm} \mathrm{~L} \times 40 \mathrm{~cm} \mathrm{~W} \times 10 \mathrm{~cm} \mathrm{D})$, including two vertical perforated acrylic glass plates as partitions covered with filter paper. These partitions are provided the lateral boundaries of the sand-filled middle compartment which has dimensions of $80 \times 40 \times 10 \mathrm{~cm}$. The purpose of the two outer compartments, i.e., influent and effluent chambers, was controlling the position of the watertable within the model aquifer deposited in the middle compartment and, in addition, controlling the wetting of this aquifer mass. Each outer compartment has dimensions of $10 \mathrm{~cm}$ long, $40 \mathrm{~cm}$ width and $10 \mathrm{~cm}$ high. The flow through the model aquifer was accomplished by storage tank of 101 volume and peristaltic pump. One value of flow rate $(120 \mathrm{ml} / \mathrm{min})$ was selected here with corresponding interstitial velocity equal to $(0.6 \mathrm{~cm} / \mathrm{min})$. Sampling plate (Fig. 2) was placed on the top of the glass tank to support the sampling ports. This plate contains three columns and two rows of sampling ports. Aqueous samples from the model aquifer were collected using stainless needles at specified periods.

The tank was packed with sandy soil as aquifer and $(\mathrm{WFS}+\mathrm{KS})$ as barrier in the configuration and alignment illustrated in Fig. 1. Monitoring of $\mathrm{Cu}^{2+}$ concentration along the length of the tank in the effluent from sampling ports was conducted for a period of 3 days. Water samples of $2 \mathrm{ml}$ volume were taken regularly (after 12, 24, 36... $72 \mathrm{~h}$ ) from these ports. For sampling the ports, six needles 


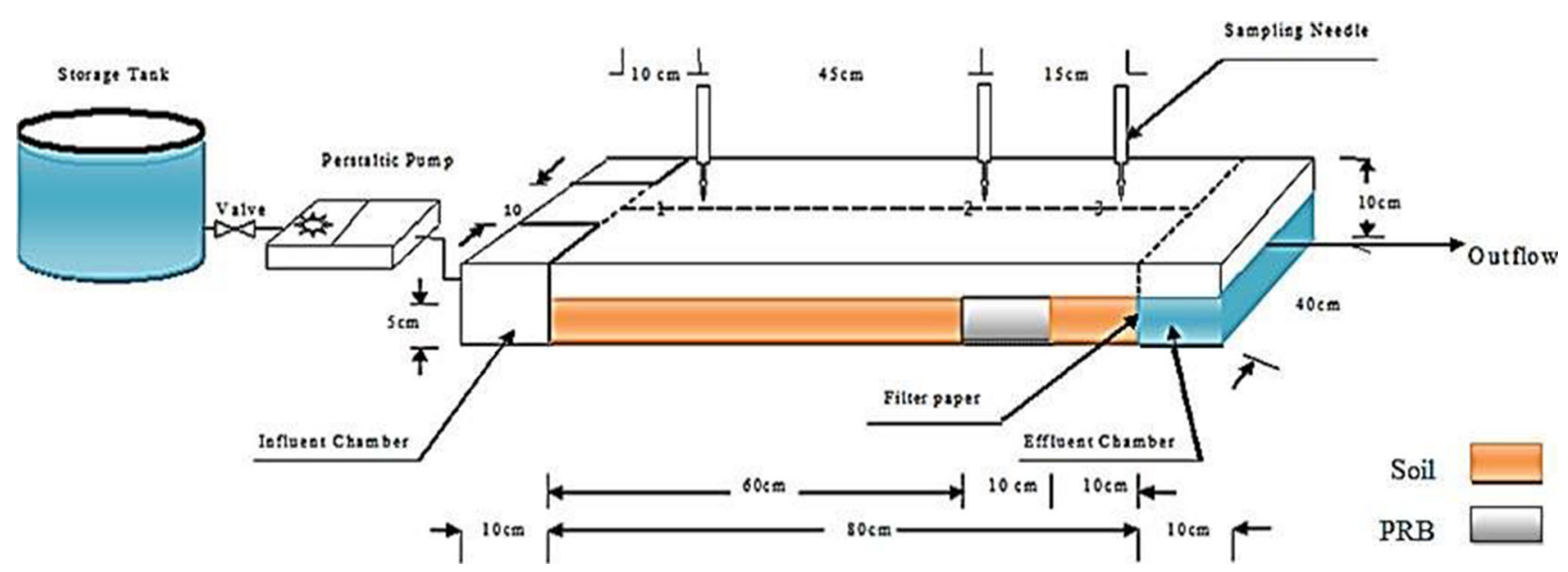

Fig. 1 Schematic diagram of the bench-scale model aquifer

Fig. 2 Schematic diagram of the sampling plate and sampling ports

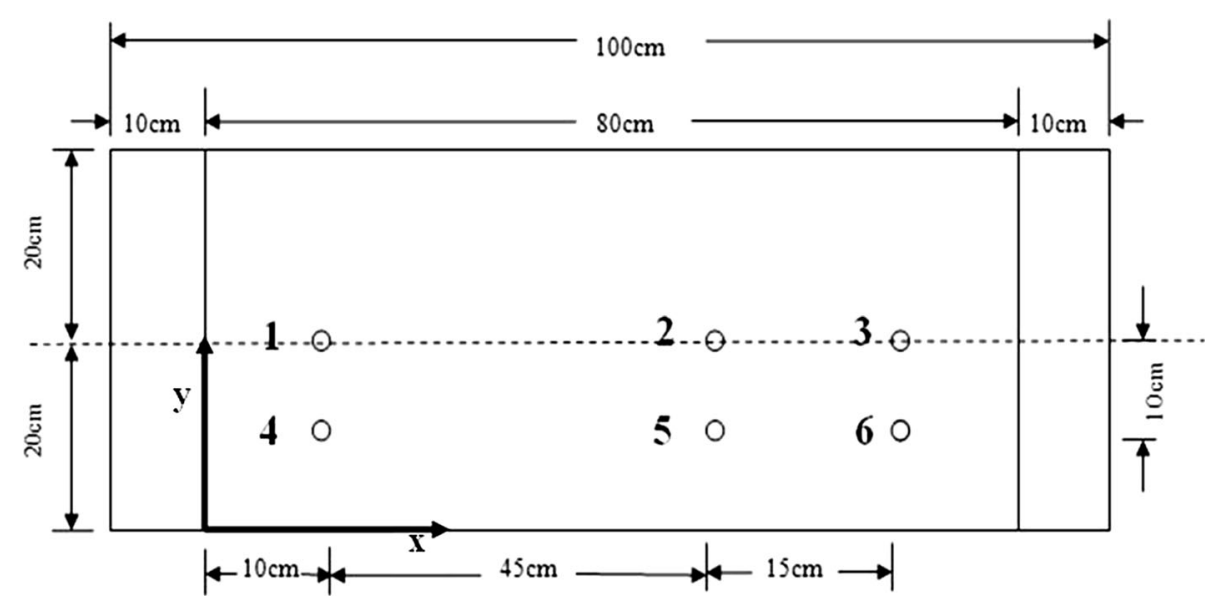

were connected to its location in each test. The samples were immediately introduced in test tubes and analyzed by AAS. The filling material in the middle compartment was assumed to be homogeneous and incompressible and constant over time for water-filled porosity. All tubing and fitting for the influent and effluent lines should be composed of an inert material.

A tracer experiment in the tank described above was performed to determine the effective dispersion coefficient for the sandy soil and (WFS + KS) using the same procedure adopted by Ujfaludi in 1986.

\section{Results and discussion}

Fourier transform infrared (FTIR) analysis

This analysis has been considered as a kind of direct means for investigating the sorption mechanisms by identifying the functional groups responsible for metal binding (Chen et al. 2008). Infrared spectra of WFS samples before and after sorption of $\mathrm{Cu}^{2+}$ were examined using (SHIMADZU FTIR, 800 series spectrophotometer). These spectra were measured within the range $4,000-400 \mathrm{~cm}^{-1}$ as shown in Fig. 3. The sorption peaks in the region of $400-750 \mathrm{~cm}^{-1}$ can be assigned to $-\mathrm{C}-\mathrm{R}$ stretching vibrations of alkyl halides group. The carboxylic stretching vibrations can be attributed to sorption peak at 1,037.70. The shifts in the IR frequencies support that carboxylic and alkyl halides groups are responsible for the sorption of copper onto WFS (Doke et al. 2012).

\section{Effect of shaking time and initial $\mathrm{pH}$ of solution}

Figure 4 shows the effect of contact time and initial $\mathrm{pH}$ of solution on $\mathrm{Cu}^{2+}$ sorption using $1 \mathrm{~g}$ of $(\mathrm{WFS}+\mathrm{KS})$ added to $100 \mathrm{ml}$ of metal solution for batch tests at $25^{\circ} \mathrm{C}$. This figure shows that the sorption rate was very fast initially and it is increased with increasing of contact time until reached the equilibrium time $(=1 \mathrm{~h})$. This may be due to 
Fig. 3 FTIR spectra of WFS $\mathbf{a}$ before and $\mathbf{b}$ after sorption
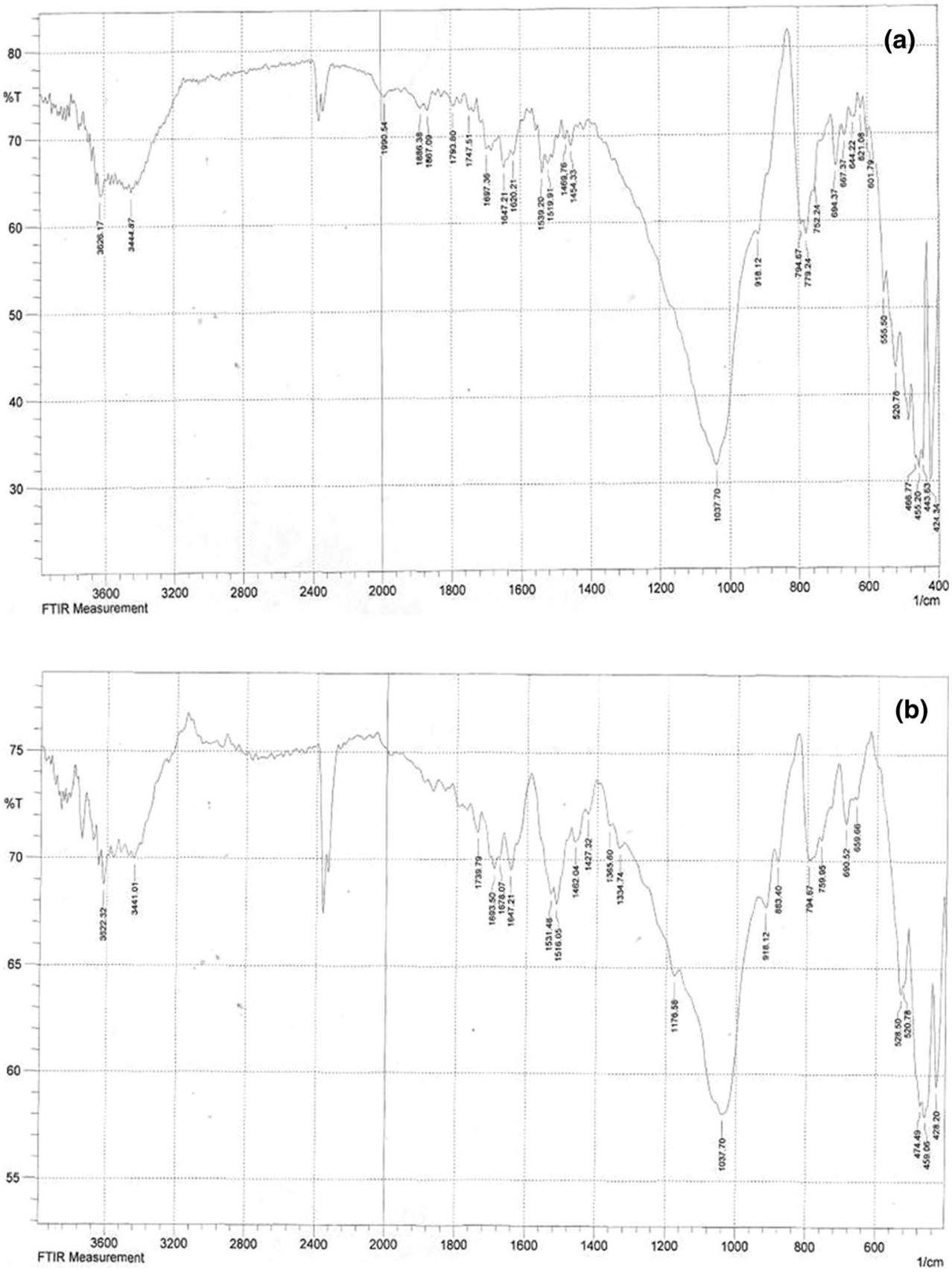

the presence of large number of adsorbent sites available for the sorption of metal ions. As the remaining vacant surfaces decreased, the sorption rate slowed down due to the formation of repulsive forces between the metals on the solid surfaces and in the liquid phase (El-Sayed et al. 2010). Also, the increase in the $\mathrm{Cu}^{2+}$ removal as the $\mathrm{pH}$ increases can be explained on the basis of a decrease in competition between proton and metal species for the surface sites, which results in a lower columbic repulsion of the sorbing metal. However, further increase in $\mathrm{pH}$ values would cause a decreasing in the removal efficiency.
This may be attributed to the formation of negative copper hydroxides which are precipitated from the solution, making true sorption studies impossible. It is clear from this figure that the maximum removal efficiency of copper was achieved at initial $\mathrm{pH}$ of 6.5 .

Effect of (WFS + KS) dose

Figure 5 illustrates the $\mathrm{Cu}^{2+}$ removal efficiency as a function of different weights of (WFS + KS) ranged from 0.25 to $5 \mathrm{~g}$ added to $100 \mathrm{ml}$ of metal solution. It can be 


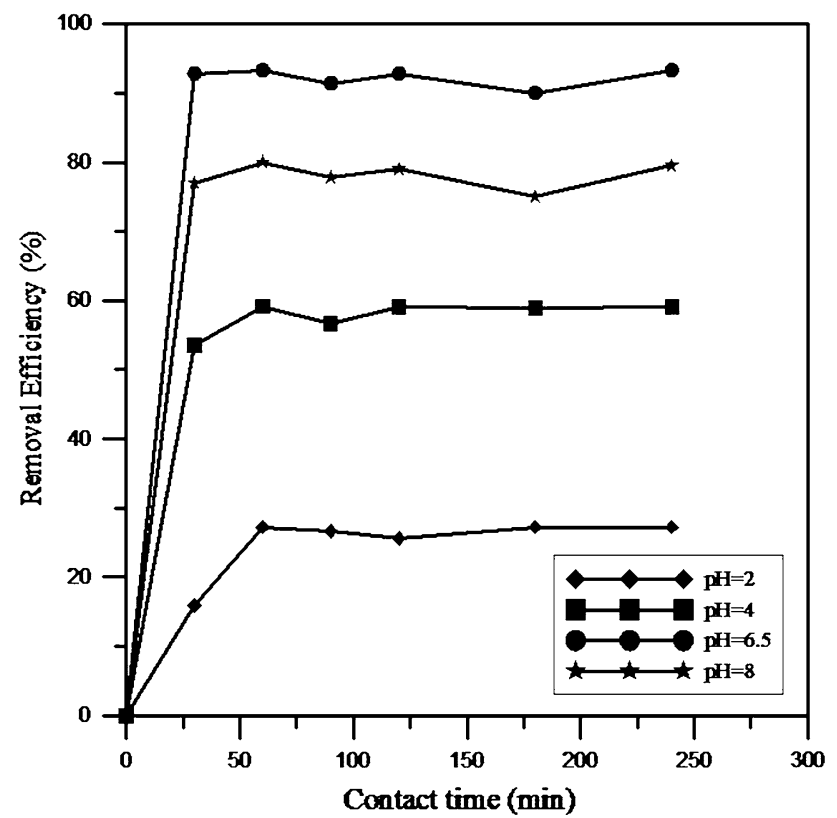

Fig. 4 Effect of initial $\mathrm{pH}$ on removal efficiency of copper by $(\mathrm{WFS}+\mathrm{KS})$ as a function of contact time $(\mathrm{Co}=50 \mathrm{mg} / \mathrm{l}$; $(\mathrm{WFS}+\mathrm{KS}) \quad$ dose $=1 \mathrm{~g} / 100 \mathrm{ml} ; \quad$ agitation $\quad$ speed $=250 \mathrm{rpm}$; $\left.T=25{ }^{\circ} \mathrm{C}\right)$

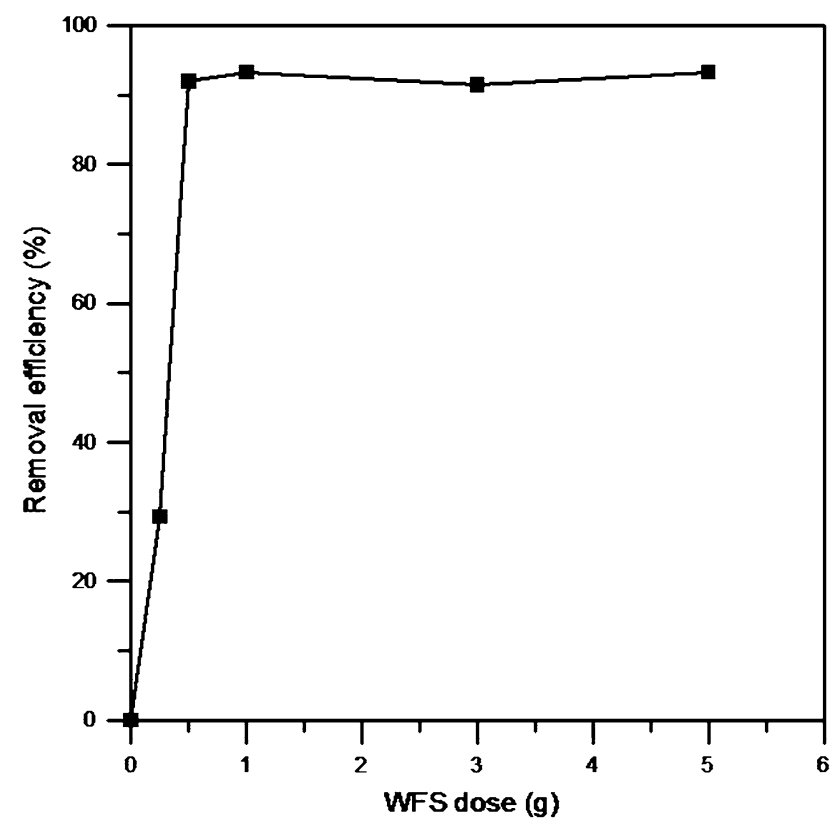

Fig. 5 Effect of WFS dosage on removal efficiency of copper $(\mathrm{Co}=50 \mathrm{mg} / \mathrm{l} ; \mathrm{pH}=6.5 ;$ agitation speed $=250 \mathrm{rpm} ;$ contact time $=1 \mathrm{~h} ; T=25^{\circ} \mathrm{C}$ )

observed that the removal efficiency improved with increasing (WFS + KS) dosage from 0.25 to $1 \mathrm{~g}$ for a fixed initial metal concentration. This was expected due to the fact that the higher dose of adsorbents in the solution, the greater availability of sorption sites.

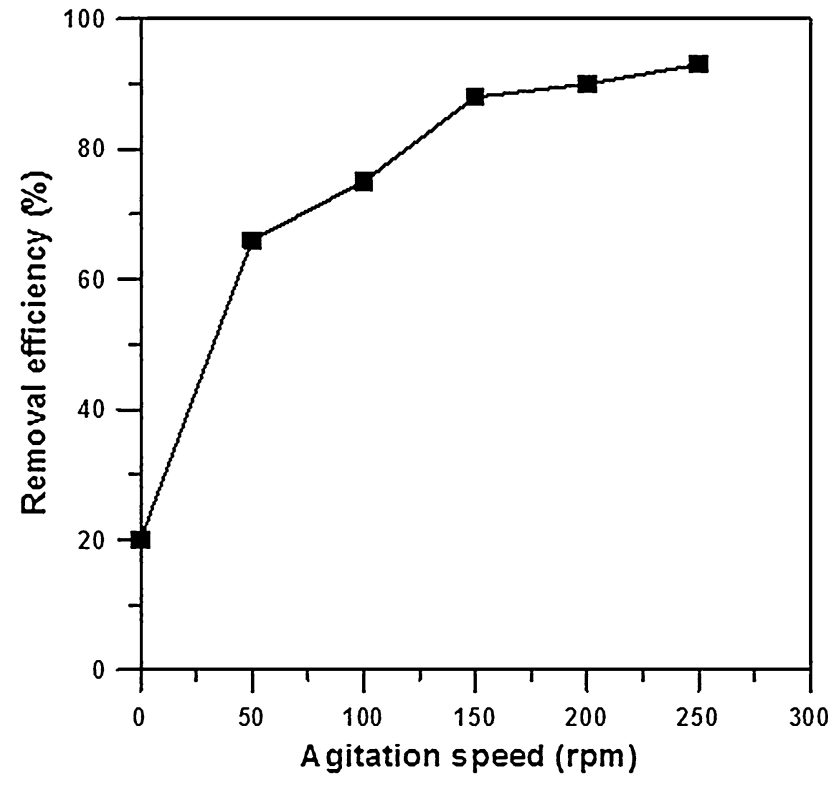

Fig. 6 Effect of agitation speed on removal efficiency of copper $(\mathrm{Co}=50 \mathrm{mg} / \mathrm{l} ; \quad \mathrm{pH}=6.5 ; \quad$ WFS $\quad$ dose $=1 \mathrm{~g} / 100 \mathrm{ml}$; contact time $=1 \mathrm{~h} ; T=25^{\circ} \mathrm{C}$ )

\section{Effect of agitation speed}

Figure 6 shows that about $20 \%$ of the copper was removed before shaking (agitation speed $=$ zero) and the uptake increases with the increase of shaking rate. There was gradual increase in metal ions uptake when agitation speed was increased from zero to $250 \mathrm{rpm}$ at which about $93 \%$ of $\mathrm{Cu}^{2+}$ has been removed. This can be attributed to improving the diffusion of ions toward the surface of the reactive media and, consequently, proper contact between ions in solution and the binding sites can be achieved.

\section{Sorption isotherms}

The sorption isotherms were produced by plotting the amount of copper removed from the solution $\left(q_{\mathrm{e}}\right.$ in $\left.\mathrm{mg} / \mathrm{g}\right)$ against the equilibrium metal concentration in the solution $\left(C_{\mathrm{e}}\right.$ in $\left.\mathrm{mg} / \mathrm{l}\right)$ at constant temperature (Hamdaouia and Naffrechoux 2007; Kumar and Kirthika 2009). The data of the batch tests are fitted with linearized form of Langmuir and Freundlich models. Accordingly, the equations of these models will be:

$q_{\mathrm{e}}=\frac{0.9053 C_{\mathrm{e}}}{1+0.096 C_{\mathrm{e}}} \quad R^{2}=0.986$

$q_{\mathrm{e}}=3.404 C_{\mathrm{e}}^{0.193} \quad R^{2}=0.978$

It is clear that these models are provided the best representation of copper sorption onto (WFS + KS) reactive material. However, the Langmuir model was 


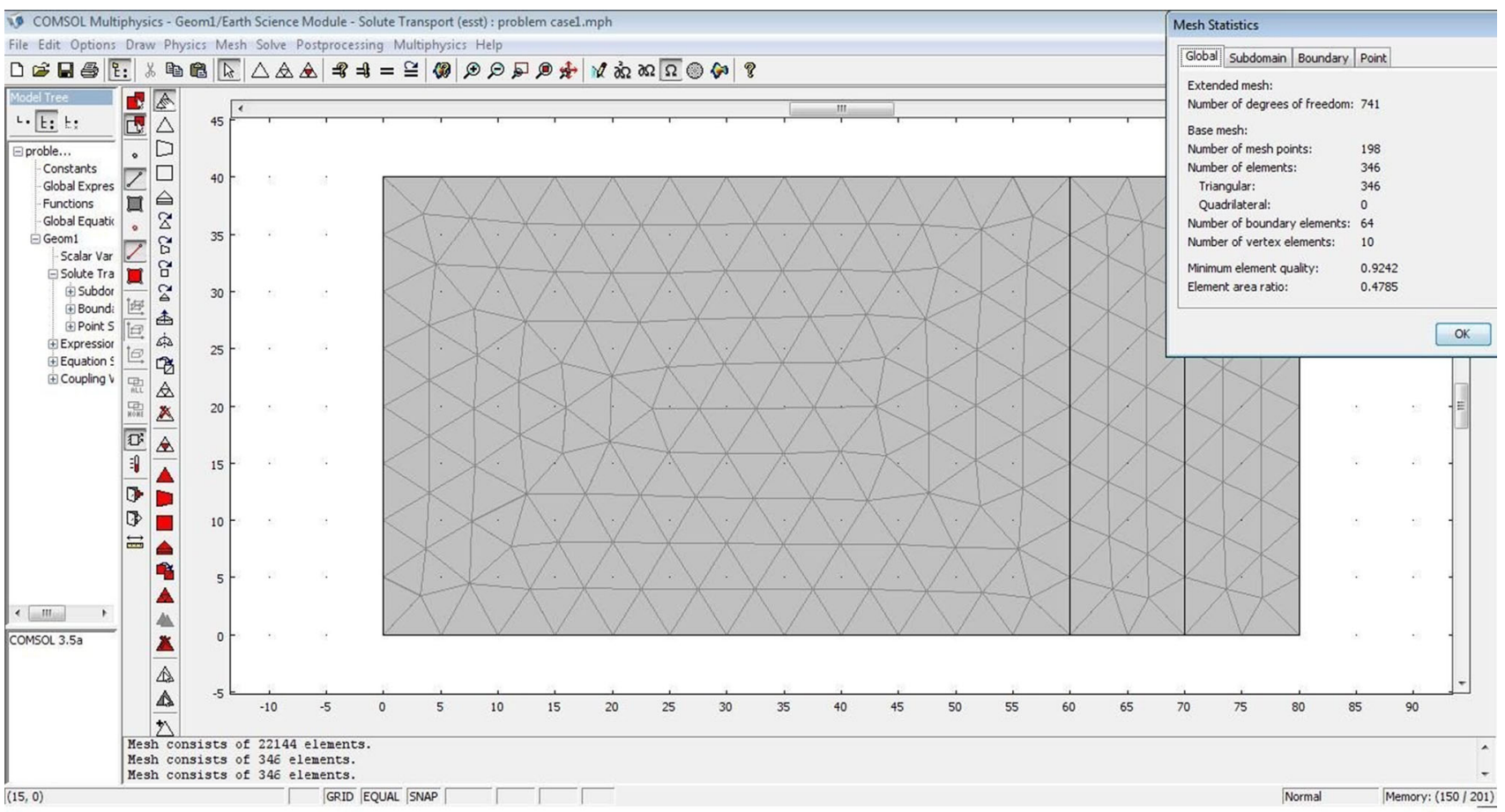

Fig. 7 Domain discretization and mesh statistics of 2D model (all dimensions in $\mathrm{cm}$ )

(a)

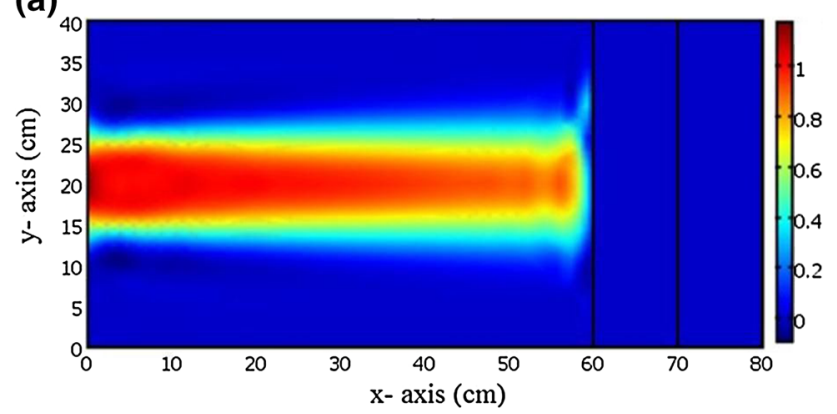

(b)

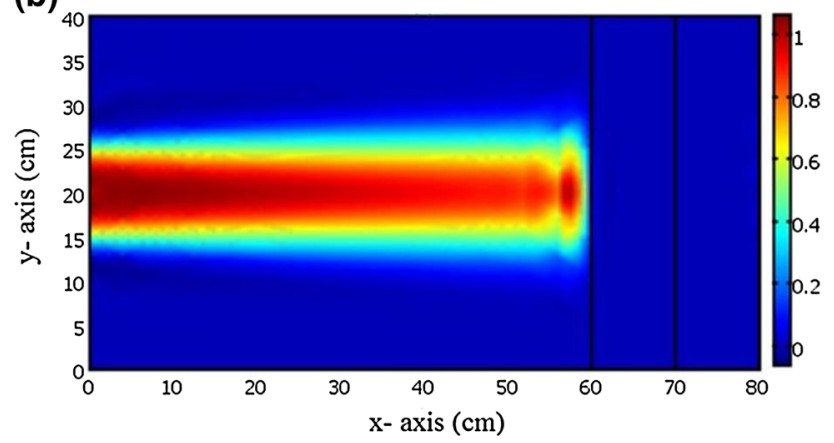

Fig. 8 Distribution of copper concentration after 7 days for flow rate equal to a 60 and b $120 \mathrm{ml} / \mathrm{min}$

chosen to describe the sorption of solute on solid in the partial differential equation governed the transport of a solute undergoing equilibrium sorption through permeable reactive barrier in the continuous mode.
Longitudinal dispersion coefficient

Results of the experimental runs concerned the measurement of longitudinal dispersion coefficient $\left(D_{\mathrm{L}}\right)$ at different values of velocity $(V)$ for soil and (WFS + KS) are taken a linear relationship as follows:

For soil, $\quad D_{\mathrm{L}}=68.16 V+0.056 R^{2}=0.973$

For $(\mathrm{WFS}+\mathrm{KS}), \quad D_{\mathrm{L}}=78.63 \mathrm{~V}+0.27 R^{2}=0.993$

These equations are taken the general form of longitudinal hydrodynamic dispersion coefficient as follows:

$D_{\mathrm{L}}=\alpha_{\mathrm{L}} V+\tau D_{\mathrm{o}}$

This means that the longitudinal dispersivity $\left(\alpha_{\mathrm{L}}\right)$ is equal to $68.16 \mathrm{~cm}$ for soil and $78.63 \mathrm{~cm}$ for mix.

\section{D PRB design-model setup}

The contaminant migration in a porous medium is due to advection-dispersion processes; therefore, considering a two-dimensional system, the dissolved copper mass balance equation may be written, as follows:

$D_{x} \frac{\partial^{2} C_{\mathrm{cu}}}{\partial x^{2}}+D_{y} \frac{\partial^{2} C_{\mathrm{cu}}}{\partial y^{2}}-V_{x} \frac{\partial C_{\mathrm{cu}}}{\partial x}=R \frac{\partial C_{\mathrm{cu}}}{\partial t}$ 

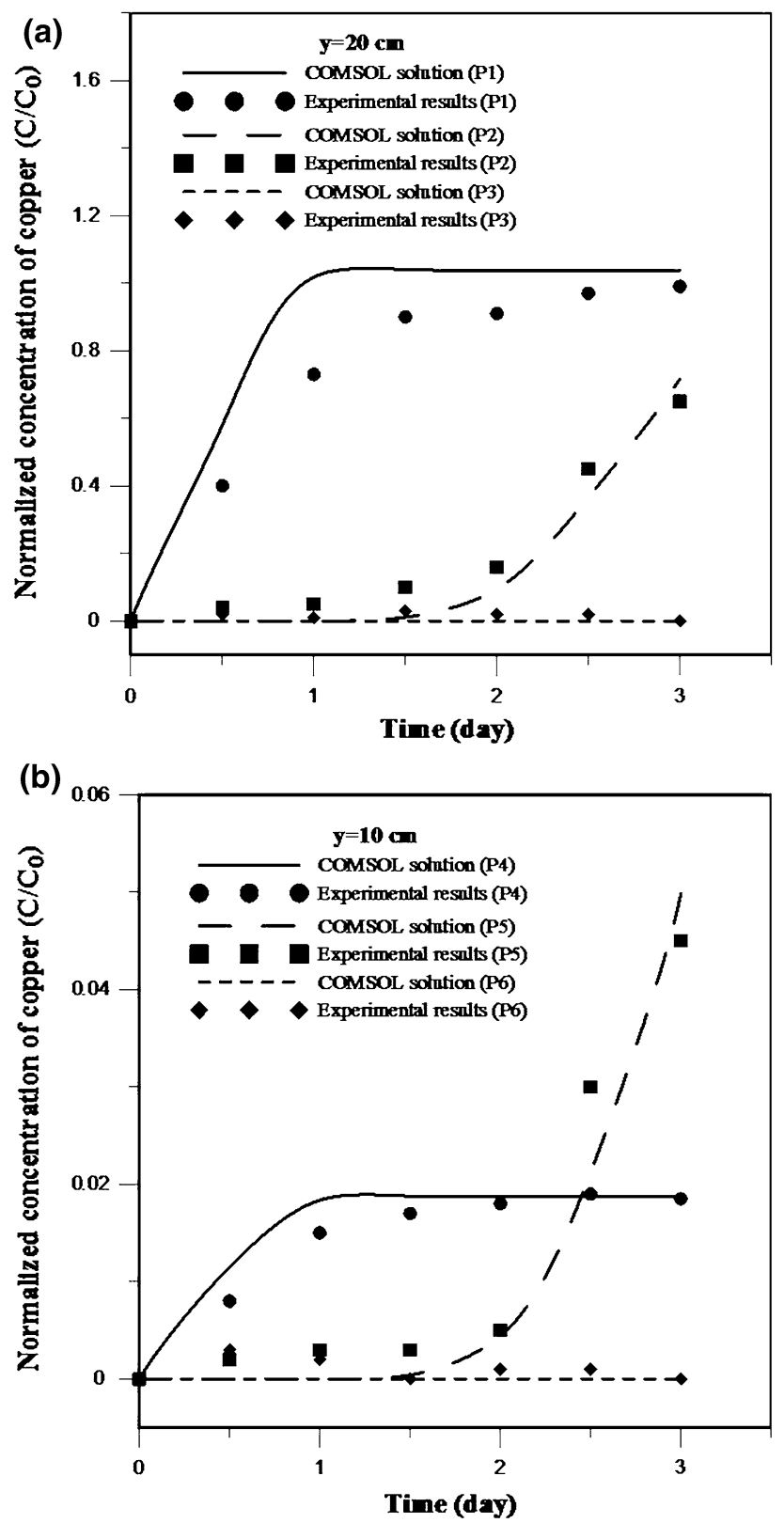

Fig. 9 Breakthrough curves as a result of the copper transport at different ports located at $\mathbf{a} y=20$ and $\mathbf{b} y=10 \mathrm{~cm}$ for flow rate $=120 \mathrm{ml} / \mathrm{min}$

where $C_{\mathrm{cu}}$ represents copper mass concentration in water and $R$ is known as the retardation factor since it has the effect of retarding the transport of adsorbed species relative to the advection front.

The initial liquid copper concentrations are assumed to be zero throughout the entire flow domain and the boundary conditions used in COMSOL Multiphysics 3.5a are reported in Eq. (10):

Lower, upper and left side boundaries: no flux/symmetry Right-side boundary: advective flux
Line source : concentration $=50 \mathrm{mg} / 1$

Interior boundaries in the barrier zone: continuity

The used mesh discretization (i.e., number of mesh points, number of elements and type of elements) is shown in Fig. 7. For the flow of contaminated groundwater through the sandy soil, the value of $R$ will be assumed equal to 1 which is reasonable for this type of soils. On the other hand, the sorption of copper on (WFS + KS) barrier is governed by Langmuir sorption isotherm and the retardation factor is expressed as:

$R=1+\frac{\rho_{d}}{n_{\mathrm{B}}}\left(\frac{0.9053}{\left(1+0.096 C_{\mathrm{cu}}\right)^{2}}\right)$

where $n_{\mathrm{B}}$ is the porosity of the barrier.

Figure 8 plotted the predicted spatial distribution of copper normalized concentration across the sand aquifer in the presence of (WFS + KS) barrier after 7 days for flow rate equal to 60 and $120 \mathrm{ml} / \mathrm{min}$. It is clear that the propagation of contaminated plume is restricted by this barrier region. Also, the value of applied flow rate, i.e., velocity of flow, plays a significant role in the extent and concentration magnitude of the contaminant plume. Accordingly, the extent of contaminant plume in the longitudinal ( $\mathrm{x}$ ) direction is greater than transverse (y) direction and highest concentrations occur in the sand bed which up-gradient of PRB. The concentration of the contaminated plume reaching the outlet may attain lower than $1.3 \mathrm{mg} / \mathrm{l}$ quality limit prescribed for surface water or drinking water (Hashim et al. 2011). The predicted values of copper concentration at the location just beyond PRB corresponding to $x=70$ and $y=20 \mathrm{~cm}$ proved that the time periods required to reach the quality limit for flow rate equal to 60 and $120 \mathrm{ml} / \mathrm{min}$ are 590 and 300 days, respectively. Also, these results showed that the thicker PRB is better than the thinner ones in copper treatment and the barrier starts to saturate with contaminant as a function of the travel time.

Comparisons between the predicted and experimental results at nodes corresponding to monitoring ports during the migration of the $\mathrm{Cu}^{2+}$ plume at different periods of time for flow rate equal to $120 \mathrm{ml} / \mathrm{min}$ using (WFS + KS) barrier are depicted in Fig. 9. Although the spatial and temporal concentration profiles are taken the same trend, concentration values in the ports (1,2 and 3) located along the centerline of the source area $(y=20 \mathrm{~cm})$ are greater than that in the ports $(4,5$ and 6$)$ deviated from the centerline by $10 \mathrm{~cm}$ (i.e., $y=10 \mathrm{~cm}$ ). Also, it is clear that the (WFS + KS) barrier have a potential functionality in the retardation of the contaminant migration in the down gradient of this barrier (concentration at ports 3 and 6 equals approximately zero). However, a reasonable agreement 
between the predicted and experimental results can be observed with mean error (ME) less than $10 \%$.

\section{Conclusion}

Depended on batch tests, there are five parameters affected on the sorption process between $\mathrm{Cu}^{2+}$ ions and reactive medium. These parameters are represented by contact time, initial $\mathrm{pH}$ of the solution, initial metal ion concentration, (WFS + KS) dose and agitation speed. The best values of these parameters that will achieve the maximum removal efficiency of $\mathrm{Cu}^{2+}(=93 \%)$ were $1 \mathrm{~h}, 6.5,50 \mathrm{mg} / \mathrm{l}, 1 \mathrm{~g} /$ $100 \mathrm{ml}$ and $250 \mathrm{rpm}$, respectively. Additionally, the sorption data of copper were correlated well by the Langmuir isotherm model with coefficient of determination $\left(R^{2}\right)$ equal to 0.986 . As proved by FTIR analysis, the carboxylic and alkyl halides groups are responsible for the sorption process.

The results of 2D numerical model solved by COMSOL Multiphysics 3.5a under equilibrium condition proved that the (WFS + KS) barrier is efficient technique in the restriction of contaminant plume. However, a good agreement between the predicted and experimental results was recognized with ME not exceeded $10 \%$.

Acknowledgments We would like to gratefully acknowledge the technical support of Environmental Engineering Department, University of Baghdad, during this work.

\section{References}

Ambrosini GSD (2004) Reactive materials for subsurface remediation through permeable reactive barriers. Ph.D Thesis, Swiss Federal Institute of Technology Zurich

Bartzas G, Komnitsas K (2010) Solid phase studies and geochemical modeling of low-cost permeable reactive barriers. J Hazard Mater 183:301-308

Bazdanis G, Komnitsas K, Sahinkaya E, Zaharaki D (2011) Removal of heavy metals from leachates using permeable reactive barriers filled with reactive organic/inorganic mixtures. In: Proceedings of the 3rd international conference on environmental management, engineering, planning, and economics (CEMEPE) \& SECOTOX conference, Skiathos island, Greece, 19-24 June

Chalermyanont T, Chetpattananondh P, Riyapan N (2013) Numerical modeling of permeable reactive barriers to treat heavy-metal contaminated groundwater. In: 6th PSU-UNS international conference on Eng. and Tech. (ICET_2013), Novi Sad, Serbia, University of Novi Sad, Faculty of Technical Sciences

Chen JP, Wang L, Zou SW (2008) Determination of lead bio-sorption properties by experimental and modeling simulation study. Chem Eng J 131:209-215

Di Natale F, Di Natale M, Greco R, Lancia A, Laudante C, Musmarra D (2008) Groundwater protection from cadmium contamination by permeable reactive barriers. J Hazard Mater 160:428-434

Doke KM, Yusufi M, Joseph RD, Khan EM (2012) Bio-sorption of hexavalent chromium onto wood apple shell: equilibrium, kinetic and thermodynamic studies. Desalin Water Treat 50:170-197

Eljamal O, Sasaki K, Hirajima T (2011) Numerical simulation for reactive solute transport of arsenic in permeable reactive barrier column including zero valent iron. Appl Math Model 35:5198-5207

El-Sayed GO, Dessouki HA, Ibrahim SS (2010) Bio-sorption of Ni(II) and $\mathrm{Cd}(\mathrm{II})$ ions from aqueous solutions onto rice straw. Chem Sci J CSJ-9

Faisal AA, Hmood ZA (2013) Groundwater protection from cadmium contamination by zeolite permeable reactive barrier. Desalin Water Treat. doi:10.1080/19443994.2013.855668

Geranio L (2007) Review of zero valent iron and apatite as reactive materials for permeable reactive barrier. Term Paper SS 07/08, major in Biogeochemistry and Pollutant Dynamics, Department of Environmental Sciences ETH Zurich

Hamdaoui O, Naffrechoux E (2007) Modeling of adsorption isotherms of phenol and chlorophenols onto granular activated carbon. J Hazard Mater 147:381-394

Hashim MA, Mukhopadhyay S, Sahu JN, Sengupta B (2011) Remediation technologies for heavy metal contaminated groundwater. J Environ Manag 92:2355-2388

Khan MS, Zaidi A, Goel R, Musarvat J (2011) Biomanagement of metal-contaminated soils. Springer, Berlin, p 20, ISBN 978-94007-1914-9

Kumar PS, Kirthika K (2009) Equilibrium and kinetic study of adsorption of nickel from aqueous solution onto bael tree leaf powder. J Eng Sci Tech 4:351-363

Lee T, Benson $\mathrm{CH}$ (2002) Using waste foundry sands as reactive media in permeable reactive barriers. Geo-engineering Rep. No. 02-01, Dept. of Civil and Environmental Engineering, Univ. of Wisconsin-Madison, Madison, WI

Lee T, Benson CH, Eykholt GR (2004) Waste green sands as reactive media for groundwater contaminated with trichloroethylene (TCE). J Hazard Mater B109:25-36

Moraci N, Calabrò PS (2010) Heavy metals removal and hydraulic performance in zero-valent iron/pumice permeable reactive barriers. J Environ Manag 91:2336-2341

National Research Council (1994) Alternatives for ground water cleanup. National Academy Press, Washington 315

Oliveira PEF, Oliveira LD, Ardisson JD, Lago RM (2011) Potential of modified iron rich foundry waste for environmental applications: fenton reaction and $\mathrm{Cr}(\mathrm{VI})$ reduction. J Hazard Mater 194:393-398

Park JB, Lee SH, Lee JW, Lee CY (2002) Lab scale experiments for permeable reactive barriers against contaminated groundwater with ammonium and heavy metals using clinoptilolite (01-29B). J Hazard Mater B95:65-79

Plamondon CO, Lynch R, Al-Tabbaa A (2011) Metal retention experiments for the design of soil-mix technology permeable reactive barriers. Clean Soil Air Water 39:844-852

Powell WW, Kenneth W, Koput J, Bowie I, Laurel SD (2002) The spatial clustering of science and capital: accounting for biotech firm - venture capital relationships. Reg Stud 36:299-313

Siddique R, Kaur G, Rajor A (2010) Waste foundry sand and its leachate characteristics. Resour Conserv Recycl 54:1027-1036

Singh A, Kuhad RC, Ward OP (2009). Advanced in applied bioremediation. Springer, Berlin Heidelberg, 17, ISBN: 978-3540-89620-3

Suponik T (2010) Adsorption and biodegradation in PRB technology. Environ Prot Eng 36:43-57

Suponik T (2013) Groundwater treatment with the use of zero-valent iron in the permeable reactive barrier technology. Physicochem Probl Miner Process 49:13-23

Ujfaludi L (1986) Longitudinal dispersion tests in non-uniform porous media. Hydrol Sci J 31:467-474 
Wang S, Nan Z, Li Y, Zhao Z (2009) The chemical bonding of copper ions on kaolin from Suzhou, China. Desalination 249:991-995

Watts RJ (1998) Hazardous wastes: sources, pathways, receptors. Wiley, New York
Woinarski AZ, Steven GW, Snape I (2006) A natural zeolite permeable reactive barrier to treat heavy-metal contaminated waters in Antarctica, kinetic and fixed bed studies. Proc Saf Environ Prot 84(B2):109-116 